\title{
The Baltic Sea Diet Score: a tool for assessing healthy eating in Nordic countries
}

\author{
Noora Kanerva ${ }^{1, *}$, Niina E Kaartinen ${ }^{1}$, Ursula Schwab ${ }^{2,3}$, Marjaana Lahti-Koski ${ }^{4}$ and \\ Satu Männistö ${ }^{1}$ \\ 'Department of Chronic Disease Prevention, National Institute for Health and Welfare, PO Box 30, Fl-00270 \\ Helsinki, Finland: ${ }^{2}$ Department of Clinical Nutrition, Institute of Public Health and Clinical Nutrition, University of \\ Eastern Finland, Kuopio, Finland: ${ }^{3}$ Institute of Clinical Medicine, Internal Medicine, Kuopio University Hospital, \\ Kuopio, Finland: ${ }^{4}$ Finnish Heart Association, Helsinki, Finland
}

Submitted 16 November 2012: Final revision received 23 July 2013: Accepted 28 July 2013: First published online 4 September 2013

\begin{abstract}
Objective: The health-related effects of the Nordic diet remain mostly unidentified. We created a Baltic Sea Diet Score (BSDS) for epidemiological research to indicate adherence to a healthy Nordic diet. We examined associations between the score and nutrient intakes that are considered important in promoting public health. We also examined the performance of the BSDS under two different cut-off strategies.

Design: The cross-sectional study included two phases of the National FINRISK 2007 Study. Diet was assessed using a validated FFQ. Food and nutrient intakes were calculated using in-house software. Nine components were selected for the score. Each component was scored according to both sex-specific consumption quartiles (BSDS-Q) and medians (BSDS-M), and summed to give the final score values.

Setting: A large representative sample of the Finnish population.

Subjects: Men ( $n$ 2217) and women ( $n$ 2493) aged 25 to 74 years.

Results: In the age- and energy-adjusted model, adherence to the diet was associated with a higher intake of carbohydrates (E\%), and lower intakes of SFA $(\mathrm{E} \%)$ and alcohol $(\mathrm{E} \%$, where $\mathrm{E} \%$ is percentage of total energy intake; $P<0 \cdot 01)$. Furthermore, the intakes of fibre, Fe, vitamins A, C and D, and folate were higher among participants who adhered to the diet $(P<0 \cdot 05)$. After further adjustments, the results remained significant $(P<0 \cdot 05)$ and did not differ remarkably between BSDS-Q and BSDS-M.

Conclusions: The BSDS can be used as a measure of a healthy Nordic diet to assess diet-health relationships in public health surveys in Nordic countries.
\end{abstract}

\author{
Keywords \\ Baltic Sea diet \\ Diet score \\ Diet quality \\ Dietary intake \\ Nordic countries
}

Nutrition is an important part of health policies due to its critical role in chronic disease prevention ${ }^{(1,2)}$. The complexity of the human diet, however, represents a challenge for studies investigating the health effects of single foods and nutrients. These studies often produce controversial results which complicates policy making ${ }^{(3,4)}$. Therefore, epidemiological research has expanded towards studying whole diets using dietary pattern methods, for example dietary scores.

A dietary score represents a summary value of eaten foods. It intends to measure adherence to a predefined (healthy) diet ${ }^{(5)}$. Thus far, several dietary scores have been related to positive health outcomes ${ }^{(6-8)}$. Dietary scores have the advantage of taking into account the complex interactions and cumulative effects of multiple foods and nutrients within the diet; consequently the health-related effects may be larger and easier to detect. In addition, the physiological complexity of chronic diseases implies that several nutrients modulate them simultaneously. These simultaneous effects may be captured by dietary scores. Furthermore, research results obtained from studies utilizing dietary scores could be transformed to comprehensible public health messages that benefit the general population, health practitioners and policy makers ${ }^{(9)}$.

Despite their many advantages, challenges in using dietary scores have appeared. Rapid expansion and development of new scores have raised concerns about the lack of uniform methodological guidelines ${ }^{(5,10)}$. The selected score components and component cut-offs vary among studies, which complicates comparing different dietary scores. Even as the scoring methodology demands unification, differences among food cultures, food resources and ecological influences require that the scores are tailored to fit local diets ${ }^{(11,12)}$. 


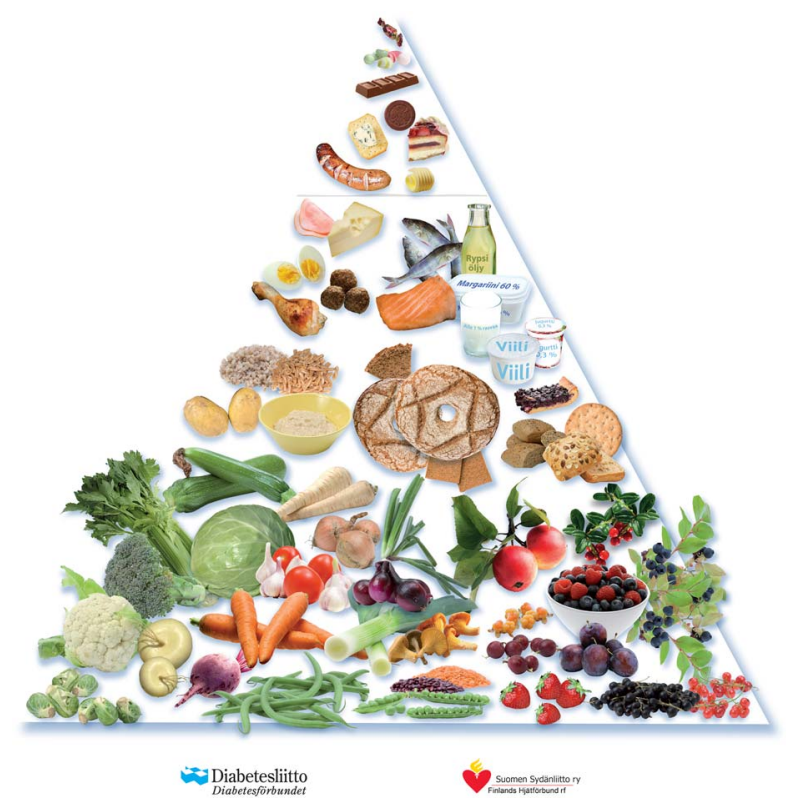

Fig. 1 The Baltic Sea Diet Pyramid (created by the Finnish Heart Association, the Finnish Diabetes Association and the University of Eastern Finland)

Although many Nordic foods are considered to have health benefits, only little is known about the healthrelated effects of the Nordic diet in its entirety ${ }^{(13-17)}$. Furthermore, the Nordic nutrition recommendations are based on single food- and nutrient-oriented research and give guidelines regarding these ${ }^{(18)}$. Therefore, the University of Eastern Finland, the Finnish Heart Association and the Finnish Diabetes Association developed a Baltic Sea Diet Pyramid (Fig. 1) based on a Nordic multicentre SYSDIET study ${ }^{(19)}$.

The Baltic Sea Diet Pyramid is addressed to the general healthy population to illustrate healthier dietary choices based on foods that are typically grown in the Nordic countries (Fig. 1). The pyramid illustrates relatively the recommended amount of foods. Foods that are crucial to health and should be consumed the most are located at the bottom: Nordic vegetables, roots, cabbages, peas, and Nordic fruits and berries. Common grains for northern latitudes (wholegrain rye, oats and barley), which have high fibre content, are located in the centre of the pyramid before fish, low-fat or fat-free milk products, and rapeseed oil. Foods that should be consumed with careful consideration are located in the top of the pyramid: processed meat, butter, sweets, chocolate and sweet bakery products. Milk and sour milk are the only drinks illustrated in the pyramid, because of their considerable role in Nordic nutrition as the source of $\mathrm{Ca}$ and protein. Water is generally recommended as a drink when thirsty. Alcohol intake should be restricted and consumed at most at a moderate consumption level.

In the present study, we designed a Baltic Sea Diet Score (BSDS) to indicate adherence to the healthy Nordic diet and examined whether the BSDS is associated with nutrient intakes that are considered important in promoting public health. Because no uniform guidelines for the creation of dietary scores exist, we also examined the performance of the BSDS under two different cut-off strategies.

\section{Materials and methods}

The study included individuals aged 25 to 74 years who participated in two phases of the National FINRISK 2007 Study. In the first phase between January and March 2007, a random sample of 10000 people was drawn from the Finnish population register in five geographical areas ${ }^{(20)}$. The sample was stratified by sex, 10-year age cohort and geographical area. Participants were mailed an invitation letter to participate in a health examination and complete a self-administered health questionnaire. Of the invited individuals, 6258 participated in the health examination (participation rate was 63\%).

To gather specific information on obesity and type 2 diabetes, all participants of the first study phase were invited to a second one, called the DIetary Lifestyle and Genetic Determinants of Obesity and Metabolic Syndrome (DILGOM) Study, between April and June 2007. The second phase included a more detailed health examination including, for example, a glucose tolerance test and body composition analysis with a bioelectric impedance scale. Participants filled in more in-depth questionnaires like the FFQ. In addition, several markers of inflammation were analysed from the blood samples. Of the invited 6258 men and women, 5024 participated (participation rate was $80 \%$ ). After exclusions of plausible under-reporters ( $n$ 48), women who were pregnant ( $n$ 26), participants with an incomplete FFQ ( $n$ 74) or missing anthropometric or background information ( $n$ 166), the sample comprised 2217 men and 2493 women.

The study was conducted according to the guidelines laid down in the Declaration of Helsinki and the ethical guidelines of the National Institute for Health and Welfare. Written informed consent was obtained from all participants, and the Ethics Committee of the Hospital District of Helsinki and Uusimaa approved the study protocol in both phases.

\section{Diet assessment}

Food consumption over the previous 12 months was assessed using a validated, self-administered, 131-item $\mathrm{FFQ}^{(21)}$ updated for the current study ${ }^{(22)}$. Participants recorded their average consumption of food items and prepared dishes in nine frequency categories ranging from 'never or seldom' to 'at least six times a day'. The participants could also report other frequently consumed foods not included on the list. The portion size was fixed for each food item and mixed dish (e.g. glass or slice). 


\begin{tabular}{|c|c|c|c|}
\hline \multirow[b]{3}{*}{ Score component } & \multirow[b]{3}{*}{ Contents } & \multicolumn{2}{|c|}{ BSDS* $^{*}$} \\
\hline & & \multicolumn{2}{|c|}{ Cut-off values } \\
\hline & & Men & Women \\
\hline Fruits and berries $(\mathrm{g} / \mathrm{d})$ & Berries, apples, pears & $32 ; 73 \ddagger ; 148$ & $50 ; 115 ; 212$ \\
\hline Vegetables $(\mathrm{g} / \mathrm{d})$ & Tomato, cucumber, cabbage, roots, peas, lettuce & $138 ; 216 ; 324$ & $177 ; 272 ; 408$ \\
\hline Cereals $(\mathrm{g} / \mathrm{d})$ & Rye, oats, barley & $49 ; 78 ; 115$ & $46 ; 75 ; 107$ \\
\hline Low-fat milk (g/d) & Fat-free milk and milk $<2 \%$ fat & $38 ; 215 ; 538$ & $28 ; 170 ; 438$ \\
\hline Fish $(g / d)$ & Salmon, freshwater fish & $26 ; 43 ; 61$ & $19 ; 30 ; 46$ \\
\hline Meat products (g/d) & Beef, pork, processed meat products, sausages & $217 ; 154 ; 105$ & $135 ; 96 ; 65$ \\
\hline Total fat $(E \%)$ & Total fat as a percentage of total energy intake & $35 ; 32 ; 28$ & $34 ; 30 ; 27$ \\
\hline Fat ratio & Ratio of PUFA to SFA+trans-fatty acids & $0.38 ; 0.46 ; 0.53$ & $0.43 ; 0.53 ; 0.74$ \\
\hline Alcohol $(g / d)+$ & Ethanol & 20 & 10 \\
\hline
\end{tabular}

BSDS, Baltic Sea Diet Score; E\%, percentage of total energy intake.

*The BSDS was calculated using the population-based consumption quartiles or medians as cut-offs.

tBecause alcohol is generally not recommended to be consumed or consumed only in moderation, it was scored similarly in both cut-off methods: men consuming $20 \mathrm{~g}$ or less and women consuming $10 \mathrm{~g}$ or less of alcohol per day received 1 point; otherwise 0 points were given $\ddagger$ Median cut-off values are the same values as the second quartile cut-off values.

The portion sizes were calculated separately for both sexes based on information from the National FINDIET Surveys ${ }^{(23)}$. The participants completed the FFQ at the study site, where a trained study nurse reviewed the questionnaire. A nutritionist entered the data into the study database, and the average daily food, nutrient and energy intakes were calculated using the national food composition (Fineli ${ }^{\circledR}$ ) database and in-house software ${ }^{(24)}$. Exclusions were made due to incompletely filled FFQ ( $n 74)$. In addition, men and women ( $n$ 48) were excluded if their daily energy intake (cut-offs) corresponded to $0.5 \%$ at either end of the daily energy-intake distribution range ${ }^{(25)}$.

Basic macronutrients, like SFA and PUFA (E\%), carbohydrates $(\mathrm{E} \%)$, sucrose $(\mathrm{E} \%)$, protein $(\mathrm{E} \%)$, alcohol $(\mathrm{E} \%)$, and also fibre were selected for analysis. Vitamin D was chosen since its intake is known to be too low in Finland $^{(26,27)}$. Furthermore, folate and Fe were included since the Finnish population, especially women at childbearing age, have too low intakes. Vitamins A and $\mathrm{C}$ were selected due to their antioxidant properties that may protect from metabolic disorders which lead to the development of chronic diseases ${ }^{(28)}$. Na was chosen because too high an intake level is one major public health concern causing hypertension ${ }^{(26)}$.

\section{The Baltic Sea Diet Score (BSDS)}

The Baltic Sea Diet Pyramid (Fig. 1) served as a template for the score. The pyramid contains ten food groups: (i) Nordic vegetables (tomato, cucumber, leafy vegetables, roots, cabbages, legumes); (ii) Nordic fruits (apples, pears, and berries); (iii) Nordic wholegrain cereals (rye, oats and barley); (iv) potatoes; (v) low-fat and fat-free milk products; (vi) Nordic fish (salmon and freshwater fish); (vii) rapeseed oil, margarine; (viii) animal fats (butter); (ix) red and processed meat (beef, pork, processed meat products and sausage); and (x) sweets. Five of these (fruits, vegetables, cereals, fish, and red and processed meat) were included directly to the BSDS (Table 1). Due to restrictions that our in-house software has set for nutrient and food intake calculations, the four other components derived from the pyramid resulted from a compromise. For example, it was not possible to derive the consumption of all low-fat and fat-free milk products, so only low-fat and fat-free milk was used. Furthermore, consumption of rapeseed oil was impossible to separate from all vegetable oils. Instead, the ratio of PUFA to SFA+trans-fatty acids (fat ratio) was used to illustrate fat quality. Also, two components which are not directly illustrated in the pyramid, but are generally part of a healthy diet were included: alcohol consumption as ethanol consumption and total fat intake, both as percentages of total energy intake ( $\mathrm{E} \%)$.

Scoring of the components was done using the proportions illustrated in the pyramid as a guideline. All components, except alcohol, were scored according to sex-specific population consumption quartiles (BSDS-Q; Table 1). To test whether the selection of cut-offs affected the results, we calculated a second BSDS using sex-specific population consumption medians (BSDS-M) as cut-offs. In BSDS-Q points were assigned according to the predictable health impact of the component. For fruits and berries, vegetables, cereals, low-fat and fat-free milk, fish and the fat ratio, the lowest quartile was coded as 0 , the second lowest as 1 , the third one as 2 and the highest quartile as 3. For meat products and total fat, the coding was done vice versa. Respectively, in BSDS-M, 0 or 1 point was assigned to the components. For alcohol, the cut-offs were assigned according to the moderate consumption level recommended in Nordic countries in both BSDS-Q and BSDS-M. Men consuming $20 \mathrm{~g}$ or less and women consuming $10 \mathrm{~g}$ or less of alcohol per day received 1 point; otherwise, 0 points were given. The resulting BSDS-Q ranged from 0 to 25 points and the BSDS-M from 0 to 9 points, with higher score values representing greater adherence to the Baltic Sea diet. 


\section{Antbropometric measurements and background variables}

At the study sites, specially trained nurses measured weight, height, waist circumference and hip circumference using standardized international protocols ${ }^{(29)}$. Height was measured to the nearest $0 \cdot 1 \mathrm{~cm}$. Body weight was measured to the nearest $0 \cdot 1 \mathrm{~kg}$, with all participants wearing light clothing and no shoes. BMI was calculated as weight in kilograms divided by the square of height in metres $\left(\mathrm{kg} / \mathrm{m}^{2}\right)$.

A self-administered questionnaire assessed participants' educational level, smoking behaviour and physical activity during leisure time. Education was measured according to the total number of school years and divided into birth-cohort specific tertiles (low, intermediate and high). Smoking behaviour was placed in four categories: never smoker, quit $\geq 0.5$ years ago, quit $<0.5$ years ago and current smoker. Leisure-time physical activity (PA) consisted of activity outside work and was assessed according into four categories: (i) inactive (mainly reading, watching television or other light activities); (ii) moderately active (walking, cycling, gardening or other activity at least $4 \mathrm{~h}$ / week); (iii) active (brisk running, walking, cross-country skiing, swimming or other physically demanding activities at least $3 \mathrm{~h} /$ week); and (iv) highly active (competition sports and physically demanding exercises done several times per week).

\section{Statistical analyses}

Data were analysed separately for men and women and for BSDS-Q and BSDS-M. All analyses were performed with the $\mathrm{R}$ statistical computing program, version $2 \cdot 13 \cdot 0^{(30)}$. A value of $P<0.05$ was considered significant. The BSDS was divided into quintiles, and in each quintile means with their standard errors or percentages were calculated for age, education, smoking, PA, BMI and energy intake. Nutrient intakes were log-transformed in order to satisfy the normality assumption and subsequently adjusted for each individual's energy intake, using the residual method ${ }^{(31)}$. Next, in each quintile means with their standard errors were calculated for age- and energy-adjusted nutrient intakes. Linear regression was used to analyse associations between the BSDS, a continuous independent variable, and nutrient intake levels, which were continuous dependent variables. The differences in mean nutrient intakes among the BSDS quintiles were analysed by ANOVA and Tukey's test. The analyses were controlled for the following potential confounders: age (in years, continuous); energy intake (kJ, continuous); education level (categorical: low, middle, high); smoking (categorical: never smoker, quit $\geq 0.5$ years ago, quit $<0.5$ years ago, current smoker); leisure-time PA (categorical: inactive, moderately active, active, highly active); and BMI ( $\mathrm{kg} / \mathrm{m}^{2}$, continuous).

To take into account possible misreporting of energy intake, we calculated the ratio of reported energy intake (EI) to predicted $\mathrm{BMR}^{(32)}$, and classified participants as either under-reporters $(\mathrm{EI}: \mathrm{BMR} \leq 1 \cdot 14)$ or plausible reporters $(\mathrm{EI}: \mathrm{BMR}>1 \cdot 14)^{(33,34)}$. Finally, we confirmed our results by re-running analyses without under-reporters.

\section{Results}

Overall, the average age of the participants was 53 years among men and 52 years among women. Participants in the highest BSDS quintile tended to be older compared with participants in the lowest quintile (Table 2). The proportion of highly educated participants, current smokers and physically inactive participants was $37 \%, 21 \%$ and $18 \%$ in men and $34 \%, 15 \%$ and $19 \%$ in women. The percentage of highly educated participants was higher, and the percentage of current smokers and inactive participants was lower, in the highest BSDS-Q quintile compared with the lowest quintile. For men, the average BMI was $27 \cdot 1 \mathrm{~kg} / \mathrm{m}^{2}$, and the daily energy intake $11700 \mathrm{~kJ}$. The respective values for women were $26 \cdot 8 \mathrm{~kg} / \mathrm{m}^{2}$ and $9440 \mathrm{~kJ}$. Furthermore, participants in the highest BSDS quintile had lower BMI and higher energy intake compared with the others.

The BSDS-Q values ranged between 2 and 25 points for both men and women (Tables 3 and 4). For men, linear regression analysis demonstrated a positive association between the BSDS-Q and lower intakes of alcohol (E\%) and SFA and PUFA (E\%), as well as a higher intake of carbohydrates (E\%; $P<0 \cdot 001)$. Sucrose intake tended to increase by score quintile, but the trend did not make a statistical difference. Compared with the lowest quintile $(P<0 \cdot 001)$, men in the fifth quintile had 1.6 percentage units lower alcohol intake and 8.5 percentage units higher carbohydrate intake. Intake of SFA was 4.9 percentage units lower, but on the contrary, the intake of PUFA was 0.3 percentage units lower in men of the fifth compared with those in the first BSDS quintile. Women had similar linear trends for energy-yielding nutrients and similar differences between the highest and the lowest quintiles $(P<0 \cdot 001)$. However, women had no linear association between BSDS-Q and PUFA intake, and sucrose intake $(\mathrm{E} \%)$ was lower in the highest score quintile of women compared with the lowest quintile $(P=0 \cdot 04)$. Intakes of fibre, vitamins A, D and C, folate, Fe and $\mathrm{Na}$ had a positive linear association with BSDS-Q in men and women $(P<0 \cdot 05)$. Moreover, the intake of these nutrients was significantly higher in the fifth quintile than the first quintile $(P<0 \cdot 001)$.

The BSDS-M values ranged from 0 to 9 points (Tables 3 and 4). The associations between the BSDS-M and nutrient intakes were generally similar to the ones derived from the BSDS-Q. However, we tended to detect a greater difference in nutrient intakes between BSDS quintiles when using median cut-offs instead of quartile cut-offs. Among men, protein intake (E\%) was significantly higher in the fifth BSDS-M quintile than in the first quintile $(P=0 \cdot 01)$ and significant linear associations emerged between BSDS-M and higher sucrose intake (E $\% ; P=0 \cdot 01)$, whereas 
Table 2 Selected characteristics of participants by BSDS-Q quintile; men ( $n$ 2217) and women $(n 2493)$ aged 25-74 years, representative of the Finnish population, Dletary Lifestyle and Genetic Determinants of Obesity and Metabolic Syndrome (DILGOM) Study, April-June 2007

\begin{tabular}{|c|c|c|c|c|c|c|c|c|c|c|c|}
\hline \multirow[b]{3}{*}{ Characteristic } & \multicolumn{10}{|c|}{ BSDS-Q quintile* } & \multirow[b]{3}{*}{$P+$} \\
\hline & \multicolumn{2}{|c|}{1} & \multicolumn{2}{|c|}{2} & \multicolumn{2}{|c|}{3} & \multicolumn{2}{|c|}{4} & \multicolumn{2}{|c|}{5} & \\
\hline & Mean & SE & Mean & SE & Mean & SE & Mean & SE & Mean & SE & \\
\hline \multicolumn{12}{|l|}{ Men } \\
\hline BSDS-Q range & \multirow{2}{*}{\multicolumn{2}{|c|}{$\begin{array}{l}2-9 \\
494\end{array}$}} & \multirow{2}{*}{\multicolumn{2}{|c|}{$\begin{array}{c}10-12 \\
540\end{array}$}} & \multirow{2}{*}{\multicolumn{2}{|c|}{$\begin{array}{c}13-14 \\
411\end{array}$}} & \multirow{2}{*}{\multicolumn{2}{|c|}{$\begin{array}{c}15-16 \\
353\end{array}$}} & \multirow{2}{*}{\multicolumn{2}{|c|}{$\begin{array}{c}17-25 \\
419\end{array}$}} & \\
\hline$n$ & & & & & & & & & & & \\
\hline Age (years) & $48 \cdot 1$ & 0.6 & $51 \cdot 3$ & 0.6 & $53 \cdot 9$ & 0.6 & $54 \cdot 9$ & 0.7 & $58 \cdot 7$ & 0.6 & $<0.001$ \\
\hline High education (\%) & \multicolumn{2}{|c|}{$29 \cdot 1$} & \multicolumn{2}{|c|}{$36 \cdot 6$} & \multicolumn{2}{|c|}{$38 \cdot 5$} & \multicolumn{2}{|c|}{$40 \cdot 5$} & \multicolumn{2}{|c|}{$42 \cdot 8$} & 0.002 \\
\hline Low physical activity (\%) & \multirow{2}{*}{\multicolumn{2}{|c|}{$\begin{array}{l}28 \cdot 7 \\
30 \cdot 6\end{array}$}} & \multirow{2}{*}{\multicolumn{2}{|c|}{$\begin{array}{l}22 \cdot 1 \\
24 \cdot 8\end{array}$}} & \multirow{2}{*}{\multicolumn{2}{|c|}{$\begin{array}{l}15 \cdot 1 \\
17 \cdot 7\end{array}$}} & \multirow{2}{*}{\multicolumn{2}{|c|}{$\begin{array}{l}12 \cdot 8 \\
12 \cdot 0\end{array}$}} & \multirow{2}{*}{\multicolumn{2}{|c|}{$\begin{array}{c}9 \cdot 2 \\
10 \cdot 0\end{array}$}} & $<0.001$ \\
\hline Current smoker (\%) & & & & & & & & & & & $<0.001$ \\
\hline BMI $\left(\mathrm{kg} / \mathrm{m}^{2}\right)$ & $27 \cdot 2$ & $0 \cdot 2$ & $27 \cdot 5$ & 0.2 & $26 \cdot 9$ & 0.2 & $27 \cdot 0$ & $0 \cdot 2$ & $27 \cdot 0$ & 0.2 & 0.07 \\
\hline Energy intake (kJ/d) & 10350 & 180 & 11270 & 170 & 11950 & 194 & 12630 & 210 & 12820 & 196 & $<0.001$ \\
\hline \multicolumn{12}{|l|}{ Women } \\
\hline BSDS-Q range & \multirow{2}{*}{\multicolumn{2}{|c|}{$\begin{array}{l}1-9 \\
567\end{array}$}} & \multirow{2}{*}{\multicolumn{2}{|c|}{$\begin{array}{c}10-12 \\
609\end{array}$}} & \multirow{2}{*}{\multicolumn{2}{|c|}{$\begin{array}{c}13-14 \\
456\end{array}$}} & \multirow{2}{*}{\multicolumn{2}{|c|}{$\begin{array}{c}15-17 \\
549\end{array}$}} & \multirow{2}{*}{\multicolumn{2}{|c|}{$\begin{array}{c}18-25 \\
397\end{array}$}} & \\
\hline$n$ & & & & & & & & & & & \\
\hline Age (years) & $46 \cdot 0$ & 0.6 & $49 \cdot 4$ & 0.5 & $52 \cdot 4$ & 0.6 & $54 \cdot 6$ & 0.5 & $58 \cdot 3$ & 0.6 & $<0.001$ \\
\hline High education (\%) & \multicolumn{2}{|c|}{$30 \cdot 7$} & \multirow{2}{*}{\multicolumn{2}{|c|}{$\begin{array}{l}35 \cdot 2 \\
19 \cdot 1\end{array}$}} & \multirow{2}{*}{\multicolumn{2}{|c|}{$\begin{array}{l}33 \cdot 6 \\
17 \cdot 0\end{array}$}} & 37 & & 37 & & $0 \cdot 014$ \\
\hline Low physical activity (\%) & & & & & & & 13 & & 10 & & $<0.001$ \\
\hline Current smoker (\%) & & & 14 & & & & 10 & & 7 & & $<0.001$ \\
\hline BMI $\left(\mathrm{kg} / \mathrm{m}^{2}\right)$ & $27 \cdot 0$ & 0.2 & $26 \cdot 8$ & 0.2 & $26 \cdot 9$ & 0.2 & $26 \cdot 8$ & $0 \cdot 2$ & $26 \cdot 5$ & $0 \cdot 2$ & 0.06 \\
\hline Energy intake (kJ/d) & 8230 & 130 & 9070 & 124 & 9370 & 142 & 10310 & 130 & 10500 & 156 & $<0.001$ \\
\hline
\end{tabular}

BSDS-Q, Baltic Sea Diet Score calculated using sex-specific population consumption quartiles.

${ }^{*}$ Values are presented as means with their standard errors except where noted. Values are adjusted for age except when age was used as dependent variable in the model.

tLinear trend across BSDS quintiles was tested with linear regression for continuous variables and with the $\chi^{2}$ test for binary background variables.

Table 3 Nutrient intakes of participants by Baltic Sea Diet Score; men ( $n$ 2217) aged 25-74 years, representative of the Finnish population, Dletary Lifestyle and Genetic Determinants of Obesity and Metabolic Syndrome (DILGOM) Study, April-June 2007

\begin{tabular}{|c|c|c|c|c|c|c|c|c|c|c|c|c|}
\hline & \multicolumn{6}{|c|}{ BSDS-Q* } & \multicolumn{6}{|c|}{ BSDS-M* ${ }^{*}$} \\
\hline & \multicolumn{2}{|c|}{ Q1 } & \multicolumn{2}{|c|}{ Q5 } & \multirow[b]{2}{*}{$P+, \ddagger$} & \multirow[b]{2}{*}{$P \S, \ddagger$} & \multicolumn{2}{|c|}{ Q1 } & \multicolumn{2}{|c|}{ Q5 } & \multirow[b]{2}{*}{$P+, \ddagger$} & \multirow[b]{2}{*}{$P \S, \ddagger$} \\
\hline & Mean & SE & Mean & $\mathrm{SE}$ & & & Mean & $\mathrm{SE}$ & Mean & $\mathrm{SE}$ & & \\
\hline$n$ & \multicolumn{2}{|c|}{512} & \multicolumn{2}{|c|}{396} & - & - & \multicolumn{2}{|c|}{537} & \multicolumn{2}{|c|}{408} & - & - \\
\hline BSDS range & \multicolumn{2}{|c|}{$2-9$} & \multicolumn{2}{|c|}{$17-25$} & - & - & \multicolumn{2}{|c|}{$0-3$} & \multicolumn{2}{|c|}{$7-9$} & - & - \\
\hline Alcohol (E\%) & $3 \cdot 8$ & 0.2 & $2 \cdot 2$ & 0.2 & $<0.001$ & $<0.001$ & $4 \cdot 2$ & 0.2 & $2 \cdot 0$ & 0.2 & $<0.001$ & $<0.001$ \\
\hline SFA (E\%) & $15 \cdot 1$ & $0 \cdot 1$ & $10 \cdot 2$ & $0 \cdot 1$ & $<0.001$ & $<0.001$ & 14.9 & $0 \cdot 1$ & $10 \cdot 6$ & $0 \cdot 3$ & $<0.001$ & $<0.001$ \\
\hline PUFA (E\%) & $6 \cdot 1$ & $0 \cdot 1$ & $5 \cdot 8$ & $0 \cdot 1$ & $<0.001$ & $<0.001$ & $6 \cdot 0$ & $0 \cdot 1$ & $5 \cdot 8$ & 0.2 & 0.001 & 0.002 \\
\hline Protein (E\%) & $17 \cdot 5$ & $0 \cdot 1$ & $18 \cdot 0$ & $0 \cdot 1$ & 0.003 & $0 \cdot 15$ & $17 \cdot 4$ & $0 \cdot 1$ & $18 \cdot 0$ & $0 \cdot 1$ & $<0.001$ & 0.01 \\
\hline Carbohydrates (E\%) & $43 \cdot 7$ & 0.2 & $52 \cdot 2$ & $0 \cdot 3$ & $<0.001$ & $<0.001$ & 43.9 & 0.2 & $52 \cdot 0$ & $0 \cdot 1$ & $<0.001$ & $<0.001$ \\
\hline Sucrose (E\%) & $8 \cdot 8$ & 0.2 & $9 \cdot 4$ & 0.2 & 0.05 & 0.46 & $8 \cdot 7$ & 0.2 & $9 \cdot 5$ & $0 \cdot 1$ & 0.01 & 0.09 \\
\hline Fibre $(g / d)$ & $20 \cdot 7$ & $0 \cdot 3$ & $36 \cdot 3$ & $0 \cdot 3$ & $<0.001$ & $<0.001$ & $21 \cdot 4$ & $0 \cdot 3$ & $35 \cdot 2$ & $0 \cdot 3$ & $<0.001$ & $<0.001$ \\
\hline Vitamin A (RE) & 1080 & 30 & 1250 & 30 & $<0.001$ & $<0.001$ & 1080 & 30 & 1230 & 31 & $<0.001$ & $<0.001$ \\
\hline Vitamin $D(\mu \mathrm{g} / \mathrm{d})$ & $8 \cdot 0$ & 0.2 & $11 \cdot 6$ & 0.2 & $<0.001$ & $<0.001$ & $8 \cdot 2$ & $0 \cdot 2$ & $11 \cdot 1$ & 0.2 & $<0.001$ & $<0.001$ \\
\hline Vitamin C (mg/d) & 128 & 3 & 228 & 4 & $<0.001$ & $<0.001$ & 128 & 3 & 221 & 4 & $<0.001$ & $<0.001$ \\
\hline Folate $(\mu \mathrm{g} / \mathrm{d})$ & 335 & 3 & 455 & 4 & $<0.001$ & $<0.001$ & 340 & 3 & 443 & 4 & $<0.001$ & $<0.001$ \\
\hline $\mathrm{Ca}(\mathrm{g} / \mathrm{d})$ & $1 \cdot 2$ & $<0 \cdot 1$ & $1 \cdot 5$ & $<0 \cdot 1$ & $<0.001$ & $<0.001$ & $1 \cdot 2$ & $<0 \cdot 1$ & $1 \cdot 5$ & $<0 \cdot 1$ & $<0.001$ & $<0.001$ \\
\hline $\mathrm{Fe}(\mathrm{mg} / \mathrm{d})$ & $14 \cdot 3$ & $0 \cdot 1$ & $17 \cdot 5$ & $0 \cdot 1$ & $<0.001$ & $<0.001$ & $14 \cdot 3$ & $0 \cdot 1$ & $17 \cdot 2$ & $0 \cdot 1$ & $<0.001$ & $<0.001$ \\
\hline $\mathrm{Na}(\mathrm{g} / \mathrm{d})$ & $3 \cdot 6$ & $<0 \cdot 1$ & $3 \cdot 7$ & $<0 \cdot 1$ & $<0.01$ & $<0.01$ & $3 \cdot 6$ & $<0 \cdot 1$ & $3 \cdot 7$ & $<0 \cdot 1$ & 0.001 & $<0.001$ \\
\hline
\end{tabular}

BSDS, Baltic Sea Diet Score; BSDS-Q, Baltic Sea Diet Score calculated using sex-specific population consumption quartiles; BSDS-M, Baltic Sea Diet Score calculated using sex-specific population consumption medians; Q1, first quartile; Q5, fifth quartile; E\%, percentage of total energy intake; RE, retinol equivalent.

*The first and the fifth quintiles of the BSDS constructed using quartile (BSDS-Q) or median (BSDS-M) cut-offs are presented as means with their standard errors. Energy-yielding nutrients were adjusted for age; other nutrients were adjusted for age and energy.

tThe trends were analysed by linear regression using the BSDS as a continuous exposure variable in the model.

$\ddagger$ Adjusted for age, education, leisure-time physical activity, smoking, BMI and energy intake (energy was excluded when testing energy-yielding nutrients).

$\S$ The differences between first and fifth quintiles were analysed by Tukey's test.

no associations emerged when using the BSDS-Q. Among women, only the BSDS-M was positively associated with protein $(\mathrm{E} \%)$ intake $(P<0 \cdot 001)$. Furthermore, Ca intake was significantly higher in the fifth BSDS-M quintile compared with the first one $(P<0 \cdot 001)$, but no associations emerged when using the BSDS-Q. Contrarily, the BSDS-M was not associated significantly with higher $\mathrm{Na}$ intake, but the BSDS-Q was. 
Table 4 Nutrient intakes of participants by Baltic Sea Diet Score; women ( $n$ 2493) aged 25-74 years, representative of the Finnish population, Dletary Lifestyle and Genetic Determinants of Obesity and Metabolic Syndrome (DILGOM) Study, April-June 2007

\begin{tabular}{|c|c|c|c|c|c|c|c|c|c|c|c|c|}
\hline & \multicolumn{6}{|c|}{ BSDS-Q* } & \multicolumn{6}{|c|}{ BSDS-M* ${ }^{*}$} \\
\hline & \multicolumn{2}{|c|}{ Q1 } & \multicolumn{2}{|c|}{ Q5 } & \multirow[b]{2}{*}{$P+, \ddagger$} & \multirow[b]{2}{*}{$P \S, \mp$} & \multicolumn{2}{|c|}{ Q1 } & \multicolumn{2}{|c|}{ Q5 } & \multirow[b]{2}{*}{$P+, \ddagger$} & \multirow[b]{2}{*}{$P \S, \ddagger$} \\
\hline & Mean & SE & Mean & SE & & & Mean & SE & Mean & SE & & \\
\hline$n$ & \multirow{2}{*}{\multicolumn{2}{|c|}{$\begin{array}{l}517 \\
2-9\end{array}$}} & \multicolumn{2}{|c|}{462} & - & - & \multicolumn{2}{|c|}{599} & \multicolumn{2}{|c|}{213} & - & - \\
\hline BSDS range & & & \multicolumn{2}{|c|}{$17-25$} & - & - & \multicolumn{2}{|c|}{$0-3$} & \multicolumn{2}{|c|}{$8-9$} & - & - \\
\hline Alcohol (E\%) & $1 \cdot 5$ & $0 \cdot 1$ & $1 \cdot 2$ & $0 \cdot 1$ & 0.002 & $<0.001$ & $2 \cdot 1$ & $0 \cdot 1$ & $0 \cdot 7$ & $0 \cdot 1$ & $<0.001$ & $<0.001$ \\
\hline SFA (E\%) & $15 \cdot 0$ & $0 \cdot 1$ & $9 \cdot 6$ & $0 \cdot 1$ & $<0.001$ & $<0.001$ & $14 \cdot 5$ & $0 \cdot 1$ & $9 \cdot 5$ & 0.2 & $<0.001$ & $<0.001$ \\
\hline PUFA (E\%) & $5 \cdot 8$ & $0 \cdot 1$ & $5 \cdot 8$ & $0 \cdot 1$ & 0.04 & -11 & $6 \cdot 0$ & $0 \cdot 1$ & $5 \cdot 5$ & $0 \cdot 1$ & $<0.001$ & $<0.001$ \\
\hline Protein (E\%) & $17 \cdot 9$ & $0 \cdot 1$ & $17 \cdot 7$ & $0 \cdot 1$ & 0.08 & -11 & $17 \cdot 5$ & $0 \cdot 1$ & $18 \cdot 0$ & $0 \cdot 1$ & $<0.001$ & $0 \cdot 19$ \\
\hline Carbohydrates (E\%) & $46 \cdot 8$ & 0.3 & $54 \cdot 3$ & $0 \cdot 3$ & $<0.001$ & $<0.001$ & $46 \cdot 5$ & 0.2 & $55 \cdot 5$ & 0.4 & $<0.001$ & $<0.001$ \\
\hline Sucrose (E\%) & $10 \cdot 6$ & 0.2 & $10 \cdot 3$ & $0 \cdot 1$ & 0.54 & 0.04 & $10 \cdot 3$ & $0 \cdot 2$ & $10 \cdot 4$ & 0.2 & $0 \cdot 80$ & -11 \\
\hline Fibre $(g / d)$ & $23 \cdot 5$ & 0.3 & $43 \cdot 7$ & 0.3 & $<0.001$ & $<0.001$ & $25 \cdot 4$ & $0 \cdot 3$ & $43 \cdot 5$ & 0.5 & $<0.001$ & $<0.001$ \\
\hline Vitamin A (RE) & 1130 & 30 & 1390 & 30 & $<0.001$ & $<0.001$ & 1160 & 30 & 1290 & 40 & $<0.001$ & 0.002 \\
\hline Vitamin D $(\mu \mathrm{g} / \mathrm{d})$ & $7 \cdot 9$ & 0.2 & $9 \cdot 9$ & 0.2 & $<0.001$ & $<0.001$ & $7 \cdot 4$ & 0.2 & $10 \cdot 2$ & 0.3 & $<0.001$ & $<0.001$ \\
\hline Vitamin $C(\mathrm{mg} / \mathrm{d})$ & 150 & 4 & 294 & 4 & $<0.001$ & $<0.001$ & 162 & 4 & 291 & 7 & $<0.001$ & $<0.001$ \\
\hline Folate $(\mu \mathrm{g} / \mathrm{d})$ & 346 & 4 & 506 & 4 & $<0.001$ & $<0.001$ & 362 & 4 & 499 & 6 & $<0.001$ & $<0.001$ \\
\hline $\mathrm{Ca}(\mathrm{g} / \mathrm{d})$ & $1 \cdot 6$ & $<0 \cdot 1$ & 1.5 & $<0.1$ & $<0.001$ & $-\|$ & $1 \cdot 4$ & $<0.1$ & $1 \cdot 7$ & $<0 \cdot 1$ & $<0.001$ & $<0.001$ \\
\hline $\mathrm{Fe}(\mathrm{mg} / \mathrm{d})$ & $14 \cdot 2$ & $0 \cdot 1$ & $18 \cdot 4$ & $0 \cdot 1$ & $<0.001$ & $<0.001$ & $14 \cdot 7$ & $0 \cdot 1$ & $18 \cdot 0$ & $0 \cdot 2$ & $<0.001$ & $<0.001$ \\
\hline $\mathrm{Na}(\mathrm{g} / \mathrm{d})$ & $3 \cdot 5$ & $<0.1$ & $3 \cdot 6$ & $<0 \cdot 1$ & 0.002 & $<0.001$ & $3 \cdot 5$ & $<0.1$ & $3 \cdot 5$ & $<0 \cdot 1$ & 0.06 & 0.36 \\
\hline
\end{tabular}

BSDS, Baltic Sea Diet Score; BSDS-Q, Baltic Sea Diet Score calculated using sex-specific population consumption quartiles; BSDS-M, Baltic Sea Diet Score calculated using sex-specific population consumption medians; Q1, first quartile; Q5, fifth quartile; E\%, percentage of total energy intake; RE, retinol equivalent.

*The first and the fifth quintiles of the BSDS constructed using quartile (BSDS-Q) or median (BSDS-M) cut-offs are presented as means with their standard errors. Energy-yielding nutrients were adjusted for age; other nutrients were adjusted for age and energy.

tThe trends were analysed by linear regression using the BSDS as a continuous exposure variable in the model.

$\ddagger$ Adjusted for age, education, leisure-time physical activity, smoking, BMI and energy intake (energy was excluded when testing energy-yielding nutrients). $\S$ The differences between first and fifth quintiles were analysed by Tukey's test.

IITukey's test was not performed since ANOVA indicated non-significant difference between BSDS quintiles.

\section{Discussion}

We created a dietary score to indicate adherence to the healthy Nordic diet and examined whether it is associated with nutrients which are considered important in promoting public health in Finland. Our results from this cross-sectional study demonstrated that higher BSDS values were associated with substantial increases in the intakes of carbohydrates (E\%) and fibre, and substantial decreases in the intakes of SFA (E\%) and alcohol (E\%). Furthermore, the BSDS was associated with higher intakes of food-derived vitamin $\mathrm{D}$, folate and $\mathrm{Fe}$. The two different cut-off strategies (quartiles $v$. median) gave generally similar results, although using the median cutoffs yielded slightly stronger associations.

The developed BSDS may facilitate research work by enhancing exploration of associations between the whole diet and diseases in large epidemiological studies, which would otherwise be complex ${ }^{(35)}$. Using the score as a research tool may also prove useful in public health promotion. The results obtained are easily interpretable for decision makers and authorities who need evidence-based facts in health policy making ${ }^{(9)}$. For example, the Healthy Eating Index, based on US nutrition recommendations, has been successfully used to produce research results for health policy purposes ${ }^{(36)}$. Furthermore, the Nordic Council of Ministers and several Nordic health organizations may utilize the BSDS in their health communication. They could give a simple diet-level health message instead of communicating specific recommendations to each nutrient. A simple message is more likely to transform into real action than many nutrient-level recommendations, especially when the message is adapted to the local food culture and supply ${ }^{(37,38)}$. Besides health policy, the food industry can effectively direct consumers' daily food choices. One way to inform consumers about the healthiness of a food product is to use a front-of-pack nutrition icon. In Finland, the most known nutrition icon is the Heart Symbol ${ }^{(39)}$. Similarly, the Nordic food industry could exploit the BSDS to indicate the healthiness and locality of the product. In the future, the BSDS may also have its place as a part of clinical consulting work of dietitians and other health professionals.

All nutrients were not associated with the BSDS in the way we expected. First, the associations between the BSDS and protein and sucrose intakes were weak or nonexistent. The small variation in protein intake in the Finnish population may explain the protein finding ${ }^{(22)}$. Similarly, most individuals get sugars evenly from natural sources, thus it may not be reasonable to expect that the BSDS associates with them. From a technical point of view, the BSDS does not include a specific component that would illustrate the intake of sugars (e.g. sucrose) and therefore it may not associate with it. Theoretically, the consumption of fruits and milk, the two most important natural sources of sugars in Finland ${ }^{(23)}$, should increase towards higher BSDS. Thus, individuals in the highest BSDS quintile are likely to get sucrose mostly from these foods. High intake 
of sugars is commonly perceived as unhealthy, because of its associations with chronic diseases, such as obesity ${ }^{(40)}$. It is equivocal, however, whether this risk is related to sugars originating from natural 'good' sources (e.g. fruits) or only to sugars originating from 'bad' sources (e.g. added sugar, sweets, chocolate and soft drinks) ${ }^{(40)}$. Consequently, all sugar in the diet may not be harmful. Second, the BSDS was negatively associated with PUFA intake. Adding total fat intake to the score could cause this result. However, the fatty acid ratio seemed to stay beneficial as the intake of SFA had a steeper decrease than that of PUFA. Third, the BSDS was positively associated with high intake of $\mathrm{Na}$, although the increase was not substantial. This finding could be due to high consumption of rye bread and fish in the fifth BSDS quintile ${ }^{(41)}$. The relationship of the BSDS and hypertension should be studied to ensure that no positive association exists.

We also explored if using different cut-off strategies makes any difference regarding the results, and found generally a minor effect. The median cut-offs tended to produce stronger associations than the quartile cut-offs. This might occur because of larger power due to larger group size. In addition, that the median cut-off score performed slightly better may be just a chance finding since there is no methodology to support one or the other strategy. In the literature, three strategies have been used to quantify score components. The Mediterranean diet scores ${ }^{(42,43)}$ use population- and sex-specific median cutoffs. Dietary scores such as the Diet Quality Index ${ }^{(44)}$ use quantiles in order to get low, intermediate and upper ranges for cut-off values. The Healthy Eating Index ${ }^{(36)}$ uses scoring proportional to the extent to which the dietary guidelines are met. Researchers might prefer single cut-off values because they are simpler and easier. On the other hand, single cut-offs cannot distinguish among associations of the outcome variables from individuals with intermediate intake levels from those with extreme intake levels. Therefore, quartile cut-offs are better suited for precise examination of the different impact levels. Various dietary scores have successfully illustrated a healthy diet regardless of the cut-off method used, however ${ }^{(45-47)}$.

The strengths of the present study included the large and representative sample. Despite this, health-conscious people tend to participate in health surveys more readily, which might have had an impact on our results. Furthermore, the study's cross-sectional design limits the conclusions that can be derived. We used a frequently validated $\mathrm{FFQ}^{(21,22,48)}$. The FFQ method has been shown to provide a valid estimate of diet quality as assessed by dietary score $^{(45)}$. However, overestimation of healthy and underestimation of unhealthy foods' consumption could have led to some misclassifications in the BSDS quintiles or weakened observed associations ${ }^{(49)}$. Our FFQ has been found to overestimate the consumption of vegetables, longchain n-3 fatty acids, carotenoids and vitamin $\mathrm{C}$, and underestimate alcohol and margarine consumption ${ }^{(48)}$. Since the FFQ has good ability to rank individuals according to relative nutrient intakes, the misreporting may not be problematic in the present study ${ }^{(21,22)}$. Vitamin and mineral supplement usage was not taken into account; but this may not influence the results however, since supplement users are likely also to have higher vitamin intakes from foods and thus be classified correctly ${ }^{(50-52)}$. Furthermore, the FFQ overestimates energy intake compared with diet records, but the results at the group level were found to be satisfactory, and all nutrient intake levels were corrected with energy intake, using the residual method ${ }^{(31)}$. The dietary score has some weaknesses. The selection of the score components is influenced by a subjective view to some extent. Methodological problems, such as inflexible nutrient calculation software or scoring based on study population cut-offs instead of some recommended intake level cut-offs, could also impact the results.

\section{Conclusion}

In conclusion, the novel BSDS provides associations with various nutrients, such as higher intakes of carbohydrates (E\%), fibre, vitamins and minerals, and lower intakes of SFA (E\%) and alcohol (E\%). Some nutrients might associate poorly with the BSDS, which needs to be taken into account when interpreting the results. Although the two cut-off methods did not yield substantially different results of nutrient intake levels in the Baltic Sea diet, the median cut-off based method is simpler to use and tends to have stronger associations with nutrient intake levels. The BSDS seems to be a valid tool to indicate a healthy diet and can be utilized to assess diet-disease relationships in public health surveys.

\section{Acknowledgements}

Sources of funding: This study was supported by the Academy of Finland (grant no. 136895 and 263836). The Academy of Finland had no role in the design, analysis or writing of this article. Conflicts of interest: The authors declare no personal or financial conflicts of interest. Authors' contributions: N.E.K. and S.M. participated in the design and conducted the research. N.K., S.M. and U.S. were responsible for creating the Baltic Sea Diet Score. S.M. and N.K. were responsible for the original study idea. N.K. performed the statistical analyses, wrote the manuscript and had primary responsibility for the final content. M.L.-K. contributed to manuscript preparation. All authors have read and approved the final manuscript.

\section{References}

1. Ministry of Social Affairs and Health (2008) Government Resolution on Development Guidelines for Health-enhancing 
Physical Activity and Nutrition. Brochures of the Ministry of Social Affairs and Health no. 2008:10eng. Helsinki: University Press.

2. World Health Organization (2003) Diet, Nutrition and the Prevention of Chronic Diseases. Report of a Joint WHO/FAO Expert Consultation. WHO Technical Report Series no. 916. Geneva: WHO.

3. Similä ME, Valsta LM, Kontto JP et al. (2011) Low-, mediumand high-glycaemic index carbohydrates and risk of type 2 diabetes in men. Br J Nutr 105, 1258-1264.

4. Vafeiadou K, Weech M, Sharma V et al. (2012) A review of the evidence for the effects of total dietary fat, saturated, monounsaturated and $n-6$ polyunsaturated fatty acids on vascular function, endothelial progenitor cells and microparticles. Br J Nutr 107, 303-324.

5. Waijers PM, Feskens EJ \& Ocke MC (2007) A critical review of predefined diet quality scores. Br J Nutr 97, 219-231.

6. Esposito K, Kastorini C, Panagiotakos DB et al. (2011) Mediterranean diet and weight loss: meta-analysis of randomized controlled trials. Metab Syndr Relat Disord $\mathbf{9}$, $1-12$.

7. Fung TT, Chiuve SE, McCullough ML et al. (2008) Adherence to a DASH-style diet and risk of coronary heart disease and stroke in women. Arch Intern Med 168, 713-720.

8. Haveman-Nies A, Tucker KL, de Groot LC et al. (2001) Evaluation of dietary quality in relationship to nutritional and lifestyle factors in elderly people of the US Framingham Heart Study and the European SENECA study. Eur J Clin Nutr 55, 870-880.

9. Rowe S, Alexander N, Almeida N et al. (2011) Food science challenge: translating the dietary guidelines for Americans to bring about real behavior change. J Food Sci 76, R29-R37.

10. Arvaniti F \& Panagiotakos DB (2008) Healthy indexes in public health practice and research: a review. Crit Rev Food Sci Nutr 48, 317-327.

11. Bere E \& Brug J (2009) Towards health-promoting and environmentally friendly regional diets - a Nordic example. Public Health Nutr 12, 91-96.

12. Mithril C, Dragsted LO, Meyer C et al. (2012) Guidelines for the New Nordic Diet. Public Health Nutr 15, 1941-1947.

13. Lankinen M, Schwab U, Kolehmainen M et al. (2011) Whole grain products, fish and bilberries alter glucose and lipid metabolism in a randomized, controlled trial: the Sysdimet study. PLoS One 6, e22646.

14. de Mello VD, Schwab U, Kolehmainen M et al. (2011) A diet high in fatty fish, bilberries and wholegrain products improves markers of endothelial function and inflammation in individuals with impaired glucose metabolism in a randomised controlled trial: the Sysdimet study. Diabetologia 54, 2755-2767.

15. Adamsson V, Reumark A, Fredriksson IB et al. (2011) Effects of a healthy Nordic diet on cardiovascular risk factors in hypercholesterolaemic subjects: a randomized controlled trial (NORDIET). J Intern Med 269, 150-159.

16. Olsen A, Egeberg R, Halkjaer J et al. (2011) Healthy aspects of the Nordic diet are related to lower total mortality. J Nutr 141, 639-644.

17. Uusitupa M, Hermansen K, Savolainen MJ et al. (2013) Effects of an isocaloric healthy Nordic diet on insulin sensitivity, lipid profile and inflammation markers in metabolic syndrome - a randomized study (SYSDIET). J Intern Med 274, 52-56.

18. Nordic Council of Ministers (editor) (2004) Nordic Nutrition Recommendations 2004, 4th ed. Copenhagen: Nord.

19. Adamsson V, Reumark A, Cederholm T et al. (2012) What is a healthy Nordic diet? Foods and nutrients in the NORDIET study. Food Nutr Res 56, doi: 10.3402/ fnr.v56i0.18189.
20. Vartiainen E, Laatikainen T, Peltonen M et al. (2010) Thirty-five-year trends in cardiovascular risk factors in Finland. Int J Epidemiol 39, 504-518.

21. Männistö S, Virtanen M, Mikkonen T et al. (1996) Reproducibility and validity of a food frequency questionnaire in a case-control study on breast cancer. J Clin Epidemiol 49, 401-409.

22. Kaartinen NE, Tapanainen H, Valsta LM et al. (2011) Relative validity of a FFQ in measuring carbohydrate fractions, dietary glycaemic index and load: exploring the effects of subject characteristics. Br J Nutr (Epublication ahead of print version).

23. Paturi M, Tapanainen $\mathrm{H}$, Reinivuo $\mathrm{H}$ et al. (2008) The National Findiet 2007 Survey. Publications of the National Public Health Institute no. B 23/2008. Helsinki: National Public Health Institute (in Finnish with English abstract).

24. Reinivuo H, Hirvonen T, Ovaskainen ML et al. (2010) Dietary survey methodology of FINDIET 2007 with a risk assessment perspective. Public Health Nutr 13, 915-919.

25. Meltzer HM, Brantsaeter AL, Ydersbond TA et al. (2008) Methodological challenges when monitoring the diet of pregnant women in a large study: experiences from the Norwegian Mother and Child Cohort Study (MoBa). Matern Child Nutr 4, 14-27.

26. Pietinen P, Paturi M, Reinivuo H et al. (2010) FINDIET 2007 Survey: energy and nutrient intakes. Public Health Nutr 13, 920-924.

27. Andersen R, Molgaard C, Skovgaard LT et al. (2005) Teenage girls and elderly women living in northern Europe have low winter vitamin D status. Eur J Clin Nutr 59, 533-541.

28. Haidara MA, Yassin HZ, Rateb M et al. (2006) Role of oxidative stress in development of cardiovascular complications in diabetes mellitus. Curr Vasc Pharmacol 4, 215-227.

29. Tolonen H, Koponen P, Aromaa A et al. (2008) Recommendations for the Health Examination Surveys in Europe. Publications of the National Public Health Institute no. B 21/ 2008. Helsinki: National Public Health Institute.

30. R Development Core Team (2012) R: A Language and Environment for Statistical Computing. Vienna: R Development Core Team, available at http://www.R-project.org/

31. Willett W \& Stampfer MJ (1986) Total energy intake: implications for epidemiologic analyses. Am J Epidemiol 124, $17-27$.

32. Food and Agriculture Organization of the United Nations/ World Health Organization/United Nations University (1985) Energy and Protein Requirements. Report of a Joint FAO/WHO/UNU Expert Consultation. WHO Technical Report Series no. 724. Geneva: WHO.

33. Goldberg GR, Black AE, Jebb SA et al. (1991) Critical evaluation of energy intake data using fundamental principles of energy physiology: 1 . Derivation of cut-off limits to identify under-recording. Eur J Clin Nutr 45, 569-581.

34. Black AE (2000) Critical evaluation of energy intake using the Goldberg cut-off for energy intake:basal metabolic rate. A practical guide to its calculation, use and limitations. Int J Obes Relat Metab Disord 24, 1119-1130.

35. Kourlaba G \& Panagiotakos DB (2009) Dietary quality indices and human health: a review. Maturitas 62, 1-8.

36. Guenther PM, Casavale KO, Reedy J et al. (2013) Update of the healthy eating index: HEI-2010. J Acad Nutr Diet 113, 569-580.

37. Nitzke S, Freeland-Graves J \& American Dietetic Association (2007) Position of the American Dietetic Association: total diet approach to communicating food and nutrition information. J Am Diet Assoc 107, 1224-1232.

38. Hornick BA, Krester AJ \& Nicklas TA (2008) Menu modeling with MyPyramid food patterns: incremental dietary changes lead to dramatic improvements in diet quality of menus. J Am Diet Assoc 108, 2077-2083. 
39. Lahti-Koski M, Helakorpi S, Olli M et al. (2012) Awareness and use of the Heart Symbol by Finnish consumers. Public Health Nutr 15, 476-482.

40. Te Morenga L, Mallard S \& Mann J (2012) Dietary sugars and body weight: systematic review and meta-analyses of randomized controlled trials and cohort studies. BMJ 346 , e7492.

41. Reinivuo H, Valsta LM, Laatikainen T et al. (2006) Sodium in the Finnish diet: II trends in dietary sodium intake and comparison between intake and 24-h excretion of sodium. Eur J Clin Nutr 60, 1160-1167.

42. Romaguera D, Norat T, Mouw T et al. (2009) Adherence to the Mediterranean diet is associated with lower abdominal adiposity in European men and women. I Nutr 139, $1728-1737$.

43. Trichopoulou A, Kouris-Blazos A, Wahlqvist ML et al. (1995) Diet and overall survival in elderly people. BMJ311, 1457-1460

44. Patterson RE, Haines PS \& Popkin BM (1994) Diet quality index: capturing a multidimensional behavior. I Am Diet Assoc 94, 57-64.

45. Benitez-Arciniega AA, Mendez MA, Baena-Diez JM et al. (2011) Concurrent and construct validity of Mediterranean diet scores as assessed by an FFQ. Public Health Nutr 14, 2015-2021.

46. Wirt A \& Collins CE (2009) Diet quality - what is it and does it matter? Public Health Nutr 12, 2473-2492.

47. Bach A, Serra-Majem L, Carrasco JL et al. (2006) The use of indexes evaluating the adherence to the Mediterranean diet in epidemiological studies: a review. Public Health Nutr 9 , 132-146.

48. Paalanen L, Männistö S, Virtanen MJ et al. (2006) Validity of a food frequency questionnaire varied by age and body mass index. J Clin Epidemiol 59, 994-1001.

49. Livingstone MB \& Black AE (2003) Markers of the validity of reported energy intake. J Nutr 133, Suppl. 3, 895S-920S.

50. Archer SL, Stamler J, Moag-Stahlberg A et al. (2005) Association of dietary supplement use with specific micronutrient intakes among middle-aged American men and women: the INTERMAP Study. J Am Diet Assoc 105, 1106-1114.

51. Reedy J, Haines PS \& Campbell MK (2005) Differences in fruit and vegetable intake among categories of dietary supplement users. J Am Diet Assoc 105, 1749-1756.

52. Mullie P, Clarys P, Hulens M et al. (2011) Socioeconomic, health, and dietary determinants of multivitamin supplements use in Belgium. Int J Public Health 56, 289-294. 